\begin{tabular}{|l|l|l|l|l|}
\hline \multirow{2}{*}{ aptara } & PRCA & prca201300133 & Dispatch: June 12, 2014 & CE: \\
\cline { 2 - 5 } & Journal & MSP No. & No. of pages: 8 & PE: XXXXX \\
\hline
\end{tabular}

\title{
Identification of immunogenic proteins of the bacterium Acinetobacter baumannii using a proteomic approach
}

\author{
Renata Fajardo Bonin ${ }^{1}$, Alex Chapeaurouge ${ }^{2}$, Jonas Perales ${ }^{2}$, José Godinho da Silva Jr. ${ }^{1}$, \\ Hilton Jorge do Nascimento ${ }^{1}$, Ana Paula D'Alincourt Carvalho Assef ${ }^{3}$ \\ and José Procópio Moreno Senna ${ }^{1}$ \\ ${ }^{1}$ Instituto de Tecnologia em Imunobiológicos, Fiocruz, Rio de Janeiro, Brazil \\ ${ }^{2}$ Laboratório de Toxinologia, Instituto Oswaldo Cruz, Fiocruz, Rio de Janeiro, Brazil \\ ${ }^{3}$ Laboratório de Pesquisa de Infecções Hospitalares, Instituto Oswaldo Cruz, Fiocruz, Rio de Janeiro, Brazil
}

Purpose: Acinetobacter baumannii is an important opportunistic pathogen that causes pneumoniae, urinary tract infections, and/or septicemia in immunocompromised patients. This pathogen is frequently associated with nosocomial outbreaks worldwide and has become particularly problematic because of its prevalence and resistance patterns to several antibiotics. In the present study, we used an immunoproteome-based approach to identify immunogenic proteins located on the surface of A. baumannii for the development of a possible immunotherapy against this devastating bacterial infection.

Experimental design: Sera from patients with $A$. baumannii infections $(n=50)$ and from a control group of healthy individuals $(n=3)$ were analyzed for reactivity against A. baumannii outer membrane proteins (OMPs) using Western blot analysis. To identify potential immunogenic proteins in A. baumannii, OMPs were separated by 2DE (2D electrophoresis), and reactive sera from infected patients were randomly selected and divided into two different pools, each containing 15 sera. Finally, MALDI-TOF/TOF mass spectrometric analysis was employed to identify the corresponding proteins.

Results: This analysis identified six immunoreactive proteins: OmpA, Omp34kDa, OprC, OprB-like, OXA-23, and ferric siderophore receptor protein. Notably, these proteins are highly abundant on the bacterial surface and involved in virulence, antibiotic resistance, and growth. Conclusions and clinical relevance: Our results support the notion that the proteins identified in the present immunoproteome study could serve as antigen candidates for the development of vaccines and passive immunotherapies against $A$. baumannii infections.

\section{Keywords:}

Acinetobacter baumannii / Hospital infection / Immunoproteomics / MALDI-TOF/TOF

Additional supporting information may be found in the online version of this article at the publisher's web-site
Received: December 26, 2013

Revised: April 8, 2014

Accepted: May 28, 2014
Correspondence: Dr. José Procópio Moreno Senna, Fundação Oswaldo Cruz, BioManguinhos, Avenida Brasil 4365, Pavilhão Rocha Lima, Manguinhos 21040-900, Rio de Janeiro, Brazil E-mail: jprocopio@bio.fiocruz.br

\footnotetext{
Abbreviations: ACTH, adrenocorticotropic hormone; CBBG, CBB G-250; Fiocruz, Fundação Oswaldo Cruz; IROMP, iron-regulated outer membrane protein; MDR, multidrug-resistant; NCBI, National Center for Biotechnology Information; OMP, outer membrane protein
}

\section{Introduction}

Acinetobacter baumannii is a Gram-negative, nonmotile coccobacillus that has been associated with outbreaks of nosocomial infections in hospitals all over the world. The main infection caused by this microorganism is nosocomial pneumonia, but $A$. baumannii has also been associated with bacteremia, urinary tract infections, meningitis, and skin and soft tissue infections [1]. The rapid emergence and global dissemination of A. baumannii as a major nosocomial pathogen is remarkable and demonstrates its successful adaptation to

Colour Online: See the article online to view Fig. 1 in colour. 


\section{Clinical Relevance}

Acinetobacter baumannii has been associated with outbreaks of nosocomial infections in hospitals all over the world. The main infection caused by this microorganism is nosocomial pneumonia, but $A$. baumannii has also been associated with bacteremia, urinary tract infections, meningitis, and skin and soft tissue infections. The rapid emergence and global dissemination of $A$. baumannii as a major nosocomial pathogen is remarkable and demonstrates the successful adaptation of $A$. baumannii to the hospital environment. Mortality rates associated with $A$. baumannii infection have been reported to be between 35 and $70 \%$ for nosocomial pneumonias and between 20 and $60 \%$ for bacteremic infections. Infections caused by $A$. baumannii have increased dramatically and become more difficult to treat because of the emergence of highly antibiotic-resistant strains. These strains exhibit resistance to multiple antibiotic classes, and most problematic are recent descriptions of pan-resistant strains that are resistant to all antibiotics used in the clinic. There is particular concern regarding the development of carbapenem resistance, predominantly against imipenem and meropenem, the most important agents for the treatment of infections by MDR A. baumannii. For these reasons, it is necessary to identify new bacterial targets for the development of novel approaches to prevent and treat infections caused by this microorganism. the 21st century hospital environment [2]. Mortality rates associated with $A$. baumannii infection have been reported to be between 35 and $70 \%$ for nosocomial pneumonias and between 20 and $60 \%$ for bacteremic infections [3]. Over the last three decades, the number of infections caused by $A$. baumannii has increased dramatically, and these infections have become more difficult to treat because of the emergence of highly antibiotic-resistant strains. These strains exhibit resistance to multiple antibiotic classes, and most problematic are recent descriptions of pan-resistant strains that are resistant to all clinically used antibiotics [4]. There is particular concern regarding the development of carbapenem resistance, mainly against imipenem and meropenem, which were introduced in 1985 and for years have been the most important agents for the treatment of infections by multidrug-resistant (MDR) A. baumannii [5]. For these reasons, it is necessary to identify new bacterial targets for the development of novel approaches to prevent and treat infections caused by this microorganism [4].

Immunization could represent a potentially effective strategy for preventing infections caused by A. baumannii; however, to date, there have been no vaccines developed for this pathogen [3]. The development of immunotherapy for the treatment of bacterial infections typically focuses on targets such as virulence and colonization factors located on the bacterial membrane surface. Among these factors are the outer membrane proteins (OMPs) that may act as potential targets for adhesion with other cells and binding of bactericidal compounds on the Gram-negative bacteria surface [6]. Moreover, OMPs are involved in antibiotic resistance, nutrient transport, cell-cell signaling, host cell attachment, and virulence in pathogenic strains [1]. The characterization of OMPs is necessary because these proteins are highly abundant and in direct contact with the host immune system, making them good antigen candidates for the development of immunotherapy [7].

The immunoproteomic approach enables the identification of pathogen antigens expressed during human infection and is a simple and efficient method to identify immunogenic proteins [7]. Proteomics, the large-scale study of proteins in a cell, tissue, or entire organism, allows for the fine description and overall characterization of protein expression [8]. Soares et al. [9] identified 37 OMPs from A. baumannii by $2 \mathrm{DE}$ analysis, but immunogenic proteins were not detected. In the present study, the 2D gel technique was used for the characterization of immunogenic proteins, followed by tandem mass spectrometric analysis and data mining for protein identification. The purpose was to identify antigens by immunoblotting with sera from $A$. baumannii infected patients. This approach led to the identification of several OMPs from $A$. baumannii that might be future targets for vaccine development.

\section{Materials and methods}

\subsection{Bacterial strain and growth conditions}

A MDR clinical strain of A. baumannii was grown overnight in Luria-Bertani broth (LB) with $50 \mu \mathrm{g} / \mathrm{mL}$ ampicillin at $37^{\circ} \mathrm{C}$ under constant shaking. Overnight culture was diluted $1: 100 \mathrm{v} / \mathrm{v}$ with fresh medium, and bacteria were grown to the exponential phase. Bacterial cells were pelleted by centrifugation at $10000 \times \mathrm{g}$ for $10 \mathrm{~min}$ at $37^{\circ} \mathrm{C}$. The supernatant was discarded, and the cell pellet was washed twice with $0.01 \mathrm{M}$ PBS, pH 7.5. Washed cells were stored at $-20^{\circ} \mathrm{C}$. 


\subsection{Membrane protein extraction of $\boldsymbol{A}$. baumannii}

The OMPs of A. baumannii were extracted by a modified previously described method [10] using 4\% Triton ${ }^{\circledR}$ X-114. Briefly, bacterial culture was pelleted by centrifugation at $10000 \times \mathrm{g}$ for $10 \mathrm{~min}$ at $37^{\circ} \mathrm{C}$. The supernatant was discarded, and the cell pellet was washed twice with 0.01 M PBS, pH 7.5. Then, $1 \mathrm{~g}$ of the pellet was suspended in $10 \mathrm{~mL}$ of ice-cold TBS $(50$ mM Tris- $\mathrm{HCl}, 150 \mathrm{mM} \mathrm{NaCl}, \mathrm{pH} 8.0$ ) containing 4\% Triton ${ }^{\circledR}$ $\mathrm{X}-114$. The mixture was stirred overnight at $4^{\circ} \mathrm{C}$ and then centrifuged at $10000 \times \mathrm{g}$ for $30 \mathrm{~min}$ at $4^{\circ} \mathrm{C}$. The supernatant was incubated at $37^{\circ} \mathrm{C}$ for $3 \mathrm{~h}$ to separate the aqueous and detergent phases. The detergent phase containing the OMPs was collected. Proteins were precipitated with cold $100 \%$ acetone for $3 \mathrm{~h}$ at $4^{\circ} \mathrm{C}$. The samples were centrifuged at $10000 \times \mathrm{g}$ for $15 \mathrm{~min}$ at $37^{\circ} \mathrm{C}$, the supernatant was discarded, and acetone was evaporated at $37^{\circ} \mathrm{C}$. The protein concentration in the extracts was determined with a Bio-Rad protein assay kit by a modified Folin-Lowry assay, as suggested by Peterson [11].

\subsection{Human sera}

Sera were collected from patients infected with Acinetobacter spp. $(n=50)$ in the period between October 2009 and December 2010 from five hospitals located in Rio de Janeiro, RJ. The identification of infected samples was performed using the automated method WalkAway Microscan (Dade Behring) or Vitek 2 (Biomerieux). All sera of patients infected with Acinetobacter spp. were analyzed individually by SDS-PAGE $12.5 \%$, followed by immunoblotting. For immunoproteomic analysis, reactive sera were randomly selected and divided into two different pools, each containing 15 sera. A pool comprising three sera was obtained from healthy individuals and served as a negative control. The collected samples were properly recorded, and the data concerning the identity of patients were kept confidential. The current project was approved by the Ethics Committee in Research of the Evandro Chagas Research Institute (IPEC) at Fundação Oswaldo Cruz (Fiocruz; protocol number 0004.0.009.000-10).

\subsection{D gel electrophoresis and immunoblotting}

The OMPs extracted from A. baumannii were analyzed by MiniProtean 3 (Bio-Rad) on $12.5 \%$ polyacrylamide gel in denaturing conditions according to Laemmli's method [12]. Sera from patients with $A$. baumannii infections $(n=50)$ and control group sera from healthy individuals $(n=3)$ were first individually analyzed for reactivity by Western blot against A. baumannii OMPs. Separated proteins were transferred from the 1DE gels to $0.45 \mathrm{~mm}$ nitrocellulose membranes (Bio-Rad), as described by Towbin et al. [13], for $90 \mathrm{~min}$ at $90 \mathrm{~V}$. The membrane was incubated with each human serum overnight at a dilution of 1:200, followed by a secondary antibody [anti-human IgG HRP conjugate (Sigma-Aldrich ${ }^{\circledR}$ ) at a dilution of $1: 15000 \mathrm{v} / \mathrm{v}$ for $3 \mathrm{~h}$. Proteins were detected using the color reagent Western Blue ${ }^{\circledR}$ Stabilized Substrate for Alkaline Phosphatase (Promega, USA).

\subsection{DE}

The OMPs of A. baumannii were also analyzed by 2D electrophoresis. Extracts containing $60 \mu \mathrm{g}$ of proteins were solubilized in $7 \mathrm{M}$ urea, $2 \mathrm{M}$ thiourea, 4\% w/v CHAPS, 1\% v/v three to ten carrier ampholytes, $1 \% \mathrm{w} / \mathrm{v}$ bromophenol blue, and $60 \mathrm{mM}$ DTT in a total volume of $125 \mu \mathrm{L}$. For IEF, the IPGphor III system was used (GE Healthcare) with $7 \mathrm{~cm}$ strips, pH 3-10 (GE Healthcare). IEF was performed at $30 \mathrm{~V}$ for $12 \mathrm{~h}$, followed by $200 \mathrm{~V}$ for $1 \mathrm{~h}, 500 \mathrm{~V}$ for $1 \mathrm{~h}, 1000 \mathrm{~V}$ for 1 $\mathrm{h}$, a gradient to $3500 \mathrm{~V}$ for $30 \mathrm{~min}$ and $18000 \mathrm{Vh}$, all at $20^{\circ} \mathrm{C}$ and $50 \mu \mathrm{A}$. After IEF separation, strips were equilibrated for $2 \times 15 \mathrm{~min}$ in equilibration buffer containing $50 \mathrm{mM}$ Tris-Cl, $\mathrm{pH} 8.8,6 \mathrm{M}$ urea, 30\% v/v glycerol, $2 \% \mathrm{w} / \mathrm{v}$ SDS, and $0.002 \%$ $\mathrm{w} / \mathrm{v}$ bromophenol blue. DTT at $1 \% \mathrm{w} / \mathrm{v}$ was added to the first equilibration step, and $2.5 \% \mathrm{w} / \mathrm{v}$ iodoacetamide was added to the second. IPG strips were then placed over a $12.5 \%$ resolving polyacrylamide gel, and electrophoresis was performed at $2.5 \mathrm{~mA}$ /gel for $30 \mathrm{~min}$, after which the current was increased to $20 \mathrm{~mA} /$ gel for $1 \mathrm{~h}$. To prepare the 2DE gels for analysis, CBB G-250 (CBBG) colloidal staining was performed according to Candiano et al. [14]. Protein profiles were analyzed with Image Scanner II software (Amersham Biosciences), and the gels were stored in $1 \%$ acetic acid.

\subsection{Immunoblotting}

Separated proteins were transferred from the 2DE gels to $0.45 \mathrm{~mm}$ nitrocellulose membranes (Bio-Rad), as described by Towbin et al. [13], for $90 \mathrm{~min}$ at $90 \mathrm{~V}$. The membranes were blocked with $10 \%$ skim milk and 1\% BSA in TBS $(25 \mathrm{mM}$ Tris- $\mathrm{HCl} \mathrm{pH} \mathrm{8.0;0.15} \mathrm{mM} \mathrm{NaCl)} \mathrm{at} \mathrm{room} \mathrm{temperature} \mathrm{for}$ $2 \mathrm{~h}$. Afterwards, the membranes were washed three times for 5 min. All washing steps were performed with TBS containing $0.05 \%$ Tween 20 . Membranes were incubated overnight with two different pools, each containing 15 sera of patients infected with A. baumannii at a dilution of $1: 200$, followed by a secondary antibody [anti-human IgG HRP conjugate (SigmaAldrich $^{\circledR}$ ) at a dilution of $1: 15000 \mathrm{v} / \mathrm{v}$ for $3 \mathrm{~h}$. Before and after the addition of the secondary antibody, the membranes were washed four times for $15 \mathrm{~min}$ in TBS containing $0.05 \%$ Tween-20. Proteins were detected using the color reagent Western Blue ${ }^{\circledR}$ Stabilized Substrate for Alkaline Phosphatase (Promega, USA). The reactions were terminated by the addition of distilled water.

\subsection{Protein digestion, peptide extraction, and MS}

Proteins spots were excised and treated for in-gel digestion. Gel pieces were washed once with $100 \% \mathrm{ACN}$ and dried in 
a vacuum centrifuge for $15 \mathrm{~min}$. Then, the gels were incubated for $60 \mathrm{~min}$ at $4^{\circ} \mathrm{C}$ in $15 \mu \mathrm{L}$ of $33 \mathrm{ng} / \mu \mathrm{L}$ trypsin (Promega, USA) diluted in $50 \mathrm{mM}$ ammonium bicarbonate. Excess trypsin was removed, and the gels were incubated at $58^{\circ} \mathrm{C}$ for $30 \mathrm{~min}$. The reactions were blocked with the addition of $1 \mu \mathrm{L}$ of $5 \% \mathrm{v} / \mathrm{v}$ formic acid. Peptides were extracted with $30 \mu \mathrm{L}$ of $5 \% \mathrm{v} / \mathrm{v}$ formic acid in $50 \% \mathrm{v} / \mathrm{v}$ ACN with sonication for $10 \mathrm{~min}$. The extractions were performed twice to achieve a final volume of approximately $60 \mu \mathrm{L}$. Samples containing the peptides were concentrated in a speed vac to approximately $10 \mu \mathrm{L}$ and finally desalted using a $\mathrm{C}_{18} \mathrm{RP}$ ZipTip (Millipore, Bedford, USA) microcolumn.

The sample solutions $(0.3 \mu \mathrm{L})$ were mixed with an equal amount of a saturated matrix solution (CHCA (Aldrich, Milwaukee, WI) $10 \mathrm{mg} / \mathrm{mL}$ in $50 \% \mathrm{ACN} / 0.1 \% \mathrm{TFA}$ ) on the target plate and allowed to dry at room temperature (dried-droplet method). Raw data for protein identification were acquired on an AB Sciex 5800 (AB Sciex, Foster City, CA) MALDI mass spectrometer (see Supporting Information for raw data). Up to 12 of the most intense ion signals with $\mathrm{S} / \mathrm{N}$ above 2 were selected as precursors for MS/MS acquisition, and common trypsin autolysis and keratine masses were excluded. External calibration in MS mode was performed using a mixture of five standard peptides: des-Arg1-Bradykinin $(m / z=904.468)$, angiotensin I ( $m / z=1296.685)$, Glu1-fibrinopeptide B $(\mathrm{m} / z=$ 1570.677), adrenocorticotropic hormone (ACTH) (18-39 clip) $(\mathrm{m} / z=2465.199)$, and ACTH (7-38 clip) $(\mathrm{m} / z=3657.929)$. MS/MS spectra were externally calibrated using known yion masses $(175.119,684.346,813.389,1056.475,1441.634)$ observed in the MS/MS spectrum of Glu1-fibrinopeptide B.

\subsection{Database search}

The tandem mass spectra were searched against all entries of NCBInr (www.ncbi.nlm.nih.gov/index.html) using the Mascot software (www.matrixscience.com). The following search parameters were used: no restrictions on species of origin or protein molecular mass, tryptic cleavage products, two tryptic missed cleavages allowed, variable modifications of cysteine (carbamidomethylation), asparagine and glutamine (deamidation), methionine (oxidation), and pyroglutamate formation at the N-terminal glutamine of peptides.

\section{Results and discussion}

In the present study, OMPs of A. baumannii were extracted by a modified method using 4\% Triton X-114 and resolved on a $1 \mathrm{D}$ gel. Individual sera of patients diagnosed with A. baumannii infection were used to identify OMPs that were recognized by the human immune system. Fifty sera of patients infected with A. baumannii were analyzed by immunoblotting with proteins resolved on 1D gels to determine the frequency of occurrence of the major immunogenic proteins in an individual serum. Examples could be seen in Fig. 1 and 1D

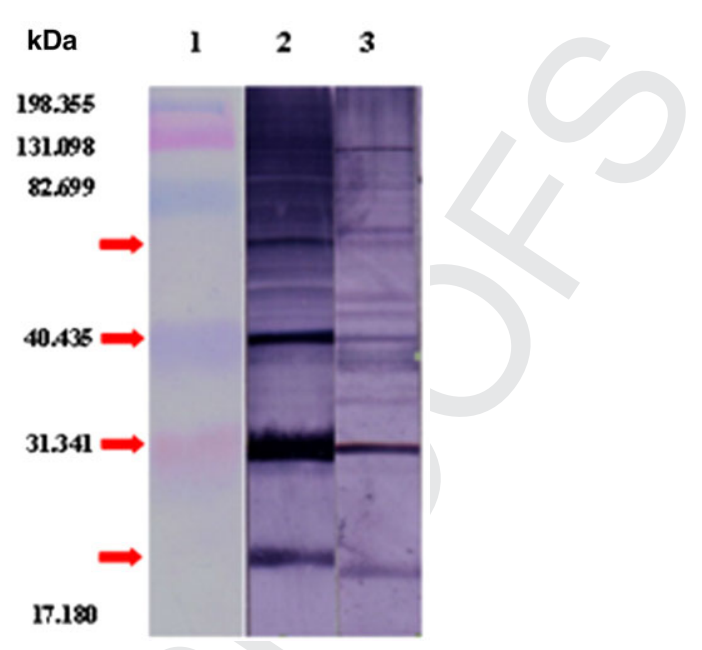

Figure 1. Representative Western blot of a 1D gel of $A$. baumannii OMPs probed with sera from patients infected with $A$. baumannii. Lane 1: standard molecular weight ladder; lanes 2 and 3: OMPs identified with serum from patients infected with Acinetobacter spp.

Table 1. Immunoreactive electrophoretic bands identified in 50 individual sera from $A$. baumannii infected patients

\begin{tabular}{ll}
\hline Molecular weight range of bands & Frequency (\%) \\
\hline $38-40$ & 88 \\
$26-27$ & 64 \\
$62-64$ & 62 \\
$32-33$ & 54 \\
$71-73$ & 52 \\
$42-44$ & 50 \\
$28-29$ & 48 \\
$30-31$ & 42 \\
$45-47$ & 42 \\
$22-23$ & 42 \\
\hline
\end{tabular}

Sera were collected from 50 individuals infected with $A$. baumannii, and immunogenic bands present in each serum were identified by immunoblotting with proteins resolved on 1D gels.

immunoblottings of all 50 patients are represented in Supporting Information Fig. 1. Healthy human sera were used as negative controls. We identified a protein with molecular weight in the range $38-40 \mathrm{kDa}$ in $88 \%$ of the sera from infected patients with Acinetobacter spp., and other proteins at lower frequency were also detected (Table 1).

To better identify A. baumannii OMPs, reactive sera from infected patients were randomly selected and divided into two different pools, each containing 15 sera for immunoproteomic analyses. First, the OMPs of A. baumannii were resolved on a 2D CBBG colloidal stained gel to yield approximately 35 spots within the $p$ I 3-10 range (Fig. 2), indicating that the 2DE analysis provided a representative view of the $A$. baumannii proteome (Supporting Information Table 1).

A total of 15 immunoreactive protein spots were observed from immunoblotting (Fig. 3A and B), and these spots matched with the protein spots observed in the preparative $2 \mathrm{D}$ 


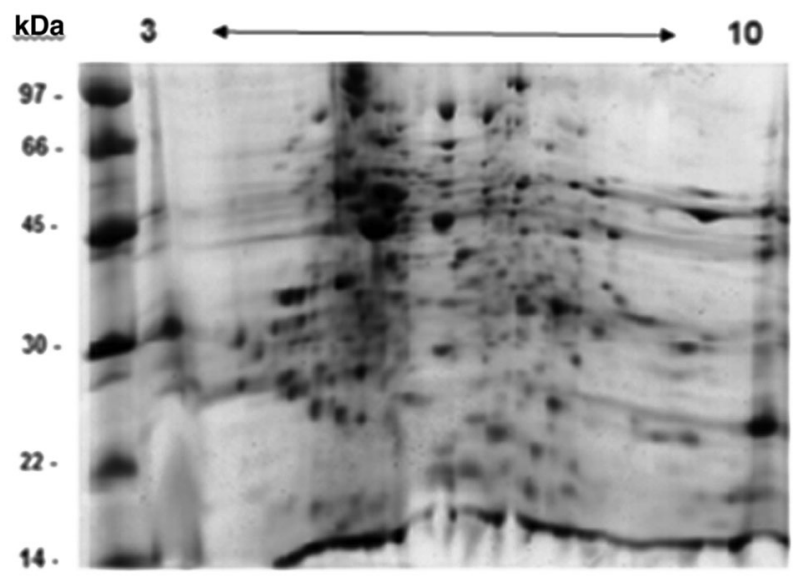

Figure 2. A 2D gel displaying $A$. baumannii OMPs proteins. Proteins identified by MALDI-TOF/TOF are indicated by spot number in Supporting Information Table 1. Preparative 2D gel of $A$. baumannii OMPs stained with CBB G-250 colloidal. Molecular size markers are indicated on the left in $\mathrm{kDa}$.

gel (Fig. 2). When the blot was probed with sera obtained from healthy individuals, no immunoreactive protein spots were observed. Protein identification was conducted using MALDIMS/MS mass spectrometric analysis of the digested proteins followed by a search against the nonredundant National Center for Biotechnology Information (NCBI) database.

Despite the large amount of proteins present in the outer membrane fraction, few were immunogenic. Some reasons can be noted:

(i) These proteins are generally embedded in the outer membrane, and therefore, only the outermost portion is in contact with the external environment. Thus, if only a few epitopes are present in the outermost region, it is normal to expect a lower immune response to these proteins in bacteria. In the $2 \mathrm{DE}$, all proteins in the extracted membrane protein were represented, including proteins not exposed to the external environment.

(ii) Some OMPs may be differentially expressed according to the environmental conditions [15], particularly during the infectious process, which is different from in vitro culture, for example.

(iii) In the $1 \mathrm{D}$ IB, we observed a low number of bands in the sera of some patients. This result may be because of the immune status of the patient, who is potentially immunocompromised [16], therefore reflecting a lower response to the surface proteins of the bacterium.

(iv) The low number of the identified immunogenic proteins may be because of the limitations of the methodology used. However, immunoproteome analyses have been employed in previous studies to identify immunogenic proteins from the sera of infected patients $[7,16]$.

(v) Kurupati et al. [7], employing immunoproteome analysis from Klebsiella pneumoniae, detected 60 proteins spots by 2DE and identified nine highly immunogenic proteins; only $15 \%$ of the spots were identified as immunogenic proteins. In our study, we detected 35 spots, and eight immunogenic proteins were identified; therefore, we conclude that our results are similar.

The immunogenic proteins identified in this work are summarized in Table 2. Among the identified proteins, some have been previously characterized and are involved in pathogenesis, metal transport (iron, copper), and antibiotic resistance.
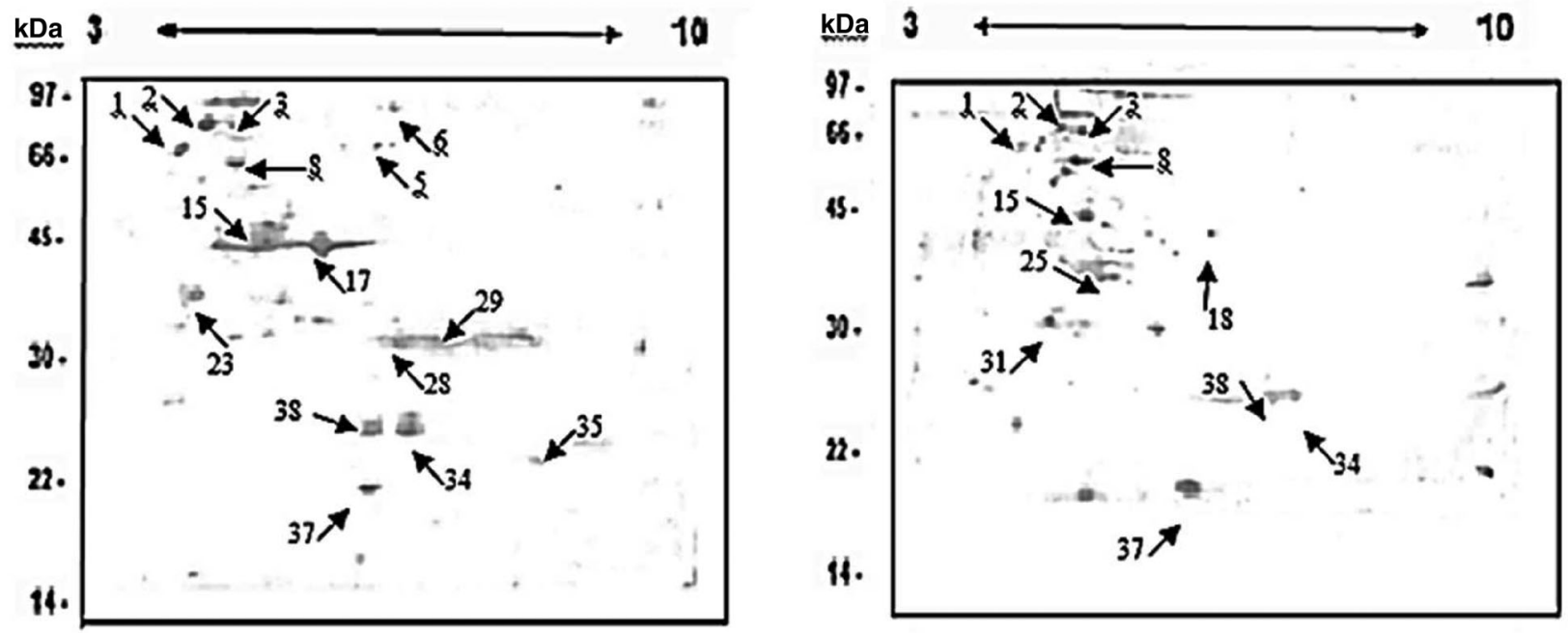

Figure 3. Acinetobacter baumannii 2D map ( $p \mid$ 3-10) with identified immunoreactive proteins (listed in Table 2). Identified proteins are indicated by spot number in Fig. 3 and Table 2. Molecular size markers are indicated on the left in kDa. (A) Western blot of a 2D gel of $A$. baumannii OMPs probed with sera pooled from 15 patients infected with $A$. baumannii. (B) Western blot of a 2D gel of OMPs probed with sera pooled from a second group of 15 patients infected with A. baumannii. All sera were diluted to 1:200. 
Table 2. Immunoreactive proteins from A. baumannii

\begin{tabular}{|c|c|}
\hline Spot & Protein \\
\hline 2 & $\begin{array}{l}\text { Outer membrane receptor (A. baumannii ACICU) gi } 184159397 \text { or TonB-dependent receptor (A. baumannii } 6014059) \text { gi } \\
332876237\end{array}$ \\
\hline 2 & Outer membrane protein (A. baumannii ATCC 17978) gi 126642014 \\
\hline 5 & Outer membrane copper receptor (OprC) (A. baumannii SDF) gi 169632179 and other proteins of Acinetobacter \\
\hline 6 & $\begin{array}{l}\text { Ferric siderophore receptor protein (A. baumannii ATCC 17978) gi 126640547, ou TonB-dependent siderophore } \\
\text { receptor ( } A \text {. baumannii OIFC137) gi } 395522750\end{array}$ \\
\hline 8 & TonB-dependent receptor (A. calcoaceticus PHEA-2) gi 375135955 \\
\hline 15 & $\begin{array}{l}\text { Outer membrane protein A (A. baumannii ATCC 17978) gi } 126642864 \text { and other "outer membrane proteins" de } \\
\text { Acinetobacter }\end{array}$ \\
\hline 17 & $\begin{array}{l}\text { Glucose-sensitive porin (OprB-like) (A. baumannii ATCC 17978) gi } 126642873 \text { ou porin B precursor (outer membrane } \\
\text { protein D1) (A. baumannii AB900) gi } 239501737\end{array}$ \\
\hline 19 & Hypothetical protein A1S_1462 (A. baumannii ATCC 17978) gi 126641508 \\
\hline 23 & 34 kDa outer membrane protein (A. baumannii ACICU) gi 184159810 \\
\hline 25 & 34 kDa outer membrane protein (A. baumannii ACICU) gi 184159810 \\
\hline 28 & $\beta$-Lactamase OXA-23 (A. baumannii AB0057) gi 213155910 ou OXA23-like protein (A. baumannii) gi 371927247 \\
\hline 29 & $\beta$-Lactamase OXA-23 (A. baumannii AB0057) gi 213155910 ou OXA23-like protein (A. baumannii) gi 371927247 \\
\hline 31 & Hypothetical protein ABAYE0137 (A. baumannii AYE) gi 169794337 \\
\hline 34 & Outer membrane protein (A. baumannii ATCC 17978) gi 126640934 and other outer membrane proteins \\
\hline 34 & $\begin{array}{l}\text { Hypothetical protein A1S_1296 (A. baumannii ATCC 17978) gi } 126641342 \text { ou type VI secretion system effector (A. } \\
\text { calcoaceticus RUH2202) gi } 262278650\end{array}$ \\
\hline 37 & $\beta$-Lactamase OXA-23 (A. baumannii AB0057) gi 213155910 ou OXA23-like protein (A. baumannii) gi 371927247 \\
\hline 38 & $\begin{array}{l}\text { Hypothetical protein A1S_1296 (A. baumannii ATCC 17978) gi } 126641342 \text { ou type VI secretion system effector (A. } \\
\text { calcoaceticus RUH2202) gi } 262278650\end{array}$ \\
\hline 38 & $\beta$-Lactamase OXA-23 (A. baumannii AB0057) gi 213155910 ou OXA23-like protein (A. baumannii) gi 371927247 \\
\hline
\end{tabular}

\subsection{OmpA}

OMPs of Gram-negative bacteria are known to be key players in bacterial adaptation and pathogenesis in host cells [18]. OMP A (OmpA), identified in this study, has previously been well characterized in A. baumannii. This protein belongs to the OmpA superfamily of proteins, which are highly conserved across multiple species of Gram-negative bacteria, and OmpA of A. baumannii is also involved in many interactions with the host during infection, including adherence to epithelial cells, induction of apoptosis in host cells, and differentiation of host immune cells [4]. According to Soares [9] and co-workers, this protein is a precursor of Omp38, of the OmpA family, which is involved in the transport of $\beta$-lactams and saccharides with molecular masses of up to 800 Da. Furthermore, it has been suggested by the same authors that this protein can act as a potential virulence factor inducing apoptosis of epithelial cells in the early stages of infection by $A$. baumannii. For these reasons, OmpA might be an attractive target for the development of novel antibacterial therapies.

\subsection{Omp34kDa}

Omp34kDa, identified in this work, has been previously observed to be located on the outer membrane of A. baumannii. Importantly, this protein was recognized by antibodies of patients with an A. baumannii infection, but not by antibodies of patients without infection or infected by other pathogens. The protein has been demonstrated to be a specific antigenic protein in OMPs of A. baumannii, but further studies are re- quired to decipher its role in the virulence or survival of the bacteria under adverse conditions [19].

\subsection{IROMP}

When colonizing a host, bacterial pathogens, including $A$. baumannii, must compete with the host for essential nutrients. One of the most coveted nutrients in biological systems is iron because of its essentiality to almost all living organisms and limited availability under physiological conditions [20]. To survive in a human host, bacteria form siderophores called iron-regulated OMPs (IROMPs) [21]. In this study, we identified the ferric siderophore receptor protein. In host tissues, the availability of free Fe is minimal because most Fe is sequestered by high-affinity iron-binding proteins, such as transferrin and lactoferrin. Notably, OmpA is potentially involved in iron metabolism. Taken together, these findings open new avenues to explore and better understand the role of iron in the pathophysiology of A. baumannii [20].

\subsection{OprC}

In the present study, OMPs associated with transport across the membrane of several compounds were also identified, including proteins such as outer membrane copper receptor (OprC), which allows the penetration of small cations and putative glucose-sensitive porin (OprB-like). This porin is often referred to as carbohydrate-selective porin because it acts as a central component of glucose, mannitol, glycerol, and fructose transport across the outer membrane [9]. 
Porins can play a variety of roles depending on the bacterial species, including the maintenance of cellular structural integrity, bacterial conjugation and bacteriophage binding, antimicrobial resistance, and pore formation to permit the penetration of small molecules [22-25].

\section{$3.5 \quad$ OXA-23}

Acinetobacter baumannii is an important opportunistic Gramnegative pathogen frequently associated with nosocomial outbreaks worldwide. Carbapenems generally represent the last resort in treating life-threatening infections caused by Acinetobacter spp. because of their resistance against most $\beta$-lactamases, including extended-spectrum $\beta$-lactamases; however, their efficacy is increasingly compromised by the emergence of carbapenem-hydrolyzing $\beta$-lactamase enzymes of Ambler molecular class B (metallo- $\beta$-lactamases) and D (oxacillinases) [26]. In this study, we identified OXA-23-like protein or $\beta$-lactamase OXA-23. The OXA-type carbapenemases have emerged globally as the main mechanism responsible for this resistance. Outbreaks of OXA-23producing Acinetobacter have been reported in various regions of the world. Although MDR Acinetobacter spp. are a leading cause of nosocomial infections in Brazilian hospitals, there are few studies regarding the mechanisms of resistance to carbapenems. Therefore, the presence of MDR OXA-23producing A. baumannii genotypes emphasizes the need to control the use of carbapenems to prevent the spread of these organisms [26].

\subsection{Hypothetical proteins of $A$. baumannii}

Three immunogenic hypothetical proteins were identified in this study. Hypothetical proteins A1S_1462 (spot 19) and A1S_1296 (spot 34), both from the ATCC 17978 strain of A. baumannii, are 242 and 167 amino acid long proteins, respectively, of unknown function. However, these proteins have sequence similarity with other protein sequences of other species of Acinetobacter, such as A. calcoaceticus, A. junii, A. johnsonii, and A. haemolyticus. Notably, hypothetical protein A1S_1296 has sequence homology with the type VI secretion system effector of A. calcoaceticus (RUH2202). AIS_1462 and A1S_1296 belong to the tetratricopeptide repeat domain and DUF superfamily.

The hypothetical protein ABAYE0137 of A. baumannii is a protein with 259 amino acids and exhibits sequence homology with other strains of A. baumannii, such as ATCC19606. ABAYE0137 belongs to the Phenol_MetA_Superfamily and is most likely involved in phenol degradation pathways.

\subsection{Immunotherapy strategies}

An important characteristic of a protein considered to be a good target for use in immunotherapy strategies is its degree of conservation in the same species (A. baumannii), in different species of Acinetobacter, and with other bacteria. This conservation ensures specific immune response against this pathogen, avoiding cross-reactivity with other microorganisms. Most of the proteins identified in this study are present in the genome of Acinetobacter deposited in Gene Bank and in another species of Acinetobacter, particularly A. calcoaceticus, A. lwoffi, A. nosocomialis, A. radioresistens, and A. johnsonii.

Infectious diseases are the second leading cause of death worldwide, and the acquisition of antibiotic resistance by many pathogenic bacteria has recently spurred interest in generating vaccines to cure or prevent diseases. OMPs are highly abundant proteins in direct contact with the host immune system, making them good targets for the development of immunotherapy for the treatment of bacterial infections [7].

The feasibility of a vaccine against $A$. baumannii has been investigated in previous studies. McConnel et al. employed a killed whole-cell $A$. baumannii vaccine that protected immunized mice from infection [27]. These results confirm the effective potential of a vaccine against A. baumannii and are complementary to our study, which identified candidate antigens for the development of a recombinant protein-based vaccine.

In this work, the characterization of OMPs based on an immunoproteomic approach identified antigen candidates by immunoblotting with sera from A. baumannii infected patients. The presence of antibodies against a particular antigen in many patients is indicative of the expression of the respective protein in vivo and demonstrates that most individuals can mount an immune response against this protein; both of these results are requirements for a successful vaccine candidate [7]. It is particularly surprising that we identified an immunogenic protein related to antimicrobial resistance; however, previous reports have identified antibodies against chromosomal $\beta$-lactamase from Pseudomonas aeruginosa isolated from infected patients [28].

\section{Conclusions}

The specific antigens OmpA, Omp34kDa, OprC, OprB-like, OXA-23, and ferric siderophore receptor protein of A. baumannii were major OMPs identified in this study as immunogenic proteins. Most of these antigens were conserved among A. baumannii and other Acinetobacter species.

These results suggest that these proteins could serve as antigen candidates for the development of immunotherapies against $A$. baumannii infections. Further studies must be performed with these immunogenic proteins to analyze their specific immunogenicities and protection abilities in animal models.

The authors thank the Samaritano hospital, the Amparo hospital (Richet laboratory), the Fernandes Figueira Institute (IFF/Fiocruz), the Universitário Pedro Ernesto hospital, the 
Universitário Antônio Pedro hospital, and the Pronto Socorro hospital (Porto Alegre) for providing sera of patients infected with Acinetobacter spp. The authors also thank the Recombinant Technology Laboratory (BioManguinhos-Fiocruz), the Laboratory of Toxinology (Fiocruz), and the PDTIS-FIOCRUZ platforms. This work was supported by grants from the Fundação de Amparo à Pesquisa do Estado do Rio de Janeiro (FAPERJ) and the Conselho Nacional de Desenvolvimento Cientifico e Tecnológico (CNPq).

The authors have declared no conflict of interest.

\section{References}

[1] Marti, S., Sanchez-Cespedes, J., Oliveira, E., Bellido, D. et al., Proteomic analysis of a fraction enriched in cell envelope proteins of Acinetobacter baumannii. Proteomics 2006, 6, 82-87.

[2] Fattahian, Y., Rasooli, I., Mousavi Gargari, S. L., Rahbar, M. R. et al., Protection against Acinetobacter baumannii infection via its functional deprivation of biofilm associated protein (Bap). Microb. Pathog. 2011, 51, 402-406.

[3] McConnell, M. J., Domínguez-Herrera, J., Smani, Y., LópezRojas, R. et al., Vaccination with outer membrane complexes elicits rapid protective immunity to multidrug-resistant Acinetobacter baumannii. Infect. Immun. 2011, 79, 518-526.

[4] McConnell, M. J., Pachon, J., Expression, purification, and refolding of biologically active Acinetobacter baumannii OmpA from Escherichia coli inclusion bodies. Protein Expr. Purif. 2011, 77, 98-103.

[5] Dijkshoorn, L., Nemec, A., Seifert, H., An increasing threat in hospitals: multidrug-resistant Acinetobacter baumannii. Nat. Rev. Microbiol. 2007, 5, 939-951.

[6] Vila, J., Marti, S., Sanchez-Cespedes, J., Porins, efflux pumps and multidrug resistance in Acinetobacter baumannii. J. Antimicrob. Chemother. 2007, 59, 1210-1215.

[7] Kurupati, P., Teh, B. K., Kumarasinghe, G., Poh, C. L., Identification of vaccine candidate antigens of an $E S B L$ producing Klebsiella pneumoniae clinical strain by immunoproteome analysis. Proteomics 2006, 6, 836-844.

[8] Soares, A. J., Santos, M. F., Trugilho, M. R., Neves-Ferreira, A. G. et al., Differential proteomics of the plasma of individuals with sepsis caused by Acinetobacter baumannii. J. Proteomics 2009, 73, 267-278.

[9] Soares, N. C., Cabral, M. P., Parreira, J. R., Gayoso, C. et al., 2$\mathrm{DE}$ analysis indicates that Acinetobacter baumannii displays a robust and versatile metabolism. Proteome Sci. 2009, 7, $1-10$.

[10] Kittelberger, R., Hansen, M. F., Hilbink, F., de Lisle, G. W. et al., Selective extraction of bacterial macromolecules by temperature-induced phase separation in Triton X-114 solution. J. Microbiol. Methods 1995, 24, 81-92.

[11] Peterson, G. L., Determination of total protein. Methods Enzymol. 1983, 91, 95-119.

[12] Laemmli, U. K., Cleavage of structural proteins during the assembly of the head of bacteriophage T4. Nature 1970, 227, 680-685.
[13] Towbin, H., Staehelin, T., Gordon, J., Electrophoretic transfer of proteins from polyacrylamide gels to nitrocellulose sheets: procedure and some applications. Proc. Natl. Acad. Sci. USA 1979, 76, 4350-4354.

[14] Candiano, G., Bruschi, M., Musante, L., Santucci, L. et al., Blue silver: a very sensitive colloidal Coomassie G-250 staining for proteome analysis. Electrophoresis 2004, 25, 1327-1333.

[15] Renzone, G., D'Ambrosio, C., Arena, S., Rullo, R. et al., Differential proteomic analysis in the study of prokaryotes stress resistance. Ann. Ist. Super. Sanita 2005, 41, 459-468.

[16] García-Garmendia, J. L., Ortiz-Leyba, C., Garnacho-Montero, J., Jiménez-Jiménez, F. J. et al., Risk factors for Acinetobacter baumannii nosocomial bacteremia in critically ill patients: a cohort study. Clin. Infect. Dis. 2001, 33, 939-946.

[17] Dennehy R., McClean, S., Immunoproteomics: the key to discovery of new vaccine antigens against bacterial respiratory infections. Curr. Protein Pept. Sci. 2012, 13, 807-815.

[18] Lin, J., Huang, S., Zhang, Q., Outer membrane proteins: key players for bacterial adaptation in host niches. Microbes Infect. 2002, 4, 325-331.

[19] Islam, A. H., Singh, K. K., Ismail, A., Demonstration of an outer membrane protein that is antigenically specific for Acinetobacter baumannii. Diagn. Microbiol. Infect. Dis. 2011, $69,38-44$.

[20] Nwugo, C. C., Gaddy, J. A., Zimbler, D. L., Actis, L. A., Deciphering the iron response in Acinetobacter baumannii: a proteomics approach. J. Proteomics 2011, 74, 44-58.

[21] Hwa, W. E., Subramaniam, G., Mansor, M. B., Yan, O. S. et al., Iron regulated outer membrane proteins (IROMPs) as potential targets against carbapenem-resistant Acinetobacterspp. isolated from a Medical Centre in Malaysia. Indian J. Med. Res. 2010, 131, 578-583.

[22] Vordermeier, H. M., Hoffmann, P., Gombert, F. O., Jung, G. et al., Synthetic peptide segments from the Escherichia coli porin $\mathrm{OmpF}$ constitute leukocyte activators. Infect. Immun. $1990,58,19-24$.

[23] Weiser, J. N., Gotschlich, E. C., Outer membrane protein A (OmpA) contributes to serum resistance and pathogenicity of Escherichia coli K-1. Infect. Immun. 1991, 59, 2252-2258.

[24] Hauschildt, S., Kleine, B., Bacterial stimulators of macrophages. Int. Rev. Cytol. 1995, 161, 263-331.

[25] Saint, N., El Hamel, C., Dé, E., Molle, G., lon channel formation by N-terminal domain: a common feature of OprFs of Pseudomonas and OmpA of Escherichia coli. FEMS Microbiol. Lett. 2000, 190, 261-265.

[26] Carvalho, K. R., Carvalho-Assef, A. P., Peirano, G., Santos, L. C. et al., Dissemination of multidrug-resistant Acinetobacter baumannii genotypes carrying bla(OXA-23) collected from hospitals in Rio de Janeiro, Brazil. Int. J. Antimicrob. Agents 2009, 34, 25-28.

[27] McConnell, M. J., Pachón, J., Active and passive immunization against Acinetobacter baumannii using an inactivated whole cell vaccine. Vaccine 2010, 29, 1-5.

[28] Giwercman, B., Rasmussen, J. W., Cioufu, O., Clemmentsen, I. et al., Antibodies against chromosomal beta-lactamase. Antimicrob. Agents Chemother. 1994, 38, 2306-2323. 


\section{Author Query Form}

\begin{tabular}{ll}
\hline Journal & PRCA \\
Article & prca201300133 \\
\hline
\end{tabular}

Dear Author

During the copy-editing of your paper, the following queries arose. Please respond to these by marking up your proofs with the necessary changes/additions. Please write your answers clearly on the query sheet if there is insufficient space on the page proofs. If returning the proof by fax do not write too close to the paper's edge. Please remember that illegible mark-ups may delay publication.

\begin{tabular}{|c|c|c|}
\hline Query No. & Description & Remarks \\
\hline Q1 & $\begin{array}{l}\text { Author: As per the standard abbreviation list, the term "2DE" has been defined as "two-dimensional } \\
\text { gel electrophoresis." Please check the term "2DE" used for "two-dimensional electrophoresis" in } \\
\text { the abstract. }\end{array}$ & \\
\hline Q2 & $\begin{array}{l}\text { Wiley: Abbreviations of all the terms ACTH, CBBG, Fiocruz, IROMP, and NCBI mentioned in the } \\
\text { article have been expanded at their first instances and their abbreviated forms have been retained } \\
\text { though they have been used only once or twice. Please check for correctness. }\end{array}$ & \\
\hline Q3 & Author: Please define 1DE. & \\
\hline Q4 & Wiley: Please check Supporting Information as typeset for correctness. & \\
\hline Q5 & Author: Please define IB. & \\
\hline Q6 & Author: Please check the terms "ou" and "de" appearing in Table 2 as typeset for correctness. & \\
\hline Q7 & $\begin{array}{l}\text { Author: Reference } 17 \text { has not been cited in the text. Please indicate where it should be cited; or } \\
\text { delete from the Reference List. }\end{array}$ & \\
\hline
\end{tabular}


Required software to e-Annotate PDFs: Adobe Acrobat Professional or Adobe Reader (version 8.0 or above). (Note that this document uses screenshots from Adobe Reader $\mathbf{X}$ )

The latest version of Acrobat Reader can be downloaded for free at: http://get.adobe.com/reader/

Once you have Acrobat Reader open on your computer, click on the Comment tab at the right of the toolbar:

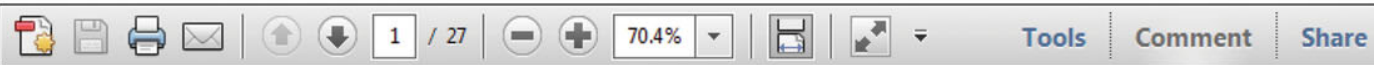

This will open up a panel down the right side of the document. The majority of tools you will use for annotating your proof will be in the Annotations section, pictured opposite. We've picked out some of these tools below:

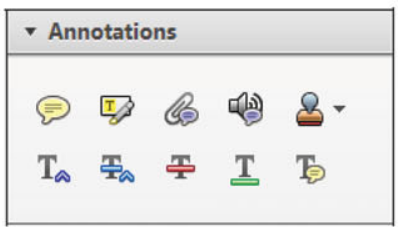

\section{Replace (Ins) Tool - for replacing text.}

Strikes a line through text and opens up a text box where replacement text can be entered.

\section{How to use it}

- Highlight a word or sentence.

- Click on the Replace (Ins) icon in the Annotations section.

- Type the replacement text into the blue box that appears.

Idard tramework for the analysis of $\mathrm{m}$ icy. Nevertheless, it alse-led to exog،

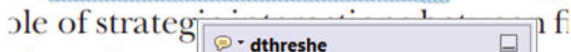
aber of comp 08/06/2011 15:58:17 $\quad$ O is that the $\mathrm{s} 1$, which led of nain compo: be level, are exc nc

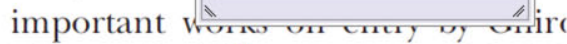
M henceforth) 1 we snen the 'hlarl b

3. Add note to text Tool - for highlighting a section to be changed to bold or italic.

T) Highlights text in yellow and opens up a text box where comments can be entered.

\section{How to use it}

- Highlight the relevant section of text.

- Click on the Add note to text icon in the Annotations section.

- Type instruction on what should be changed regarding the text into the yellow box that annears.

namic responses of mark ups ent with the VAR evidence

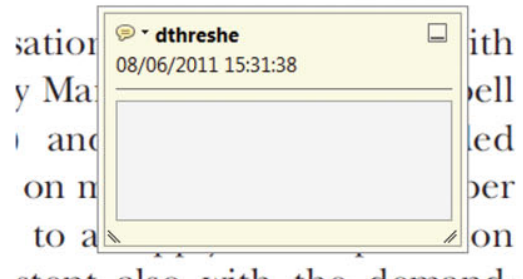

2. Strikethrough (Del) Tool - for deleting text.

空

Strikes a red line through text that is to be deleted.

How to use it

- Highlight a word or sentence.

- Click on the Strikethrough (Del) icon in the Annotations section.

there is no room for extra prohts al s ups are zero and the number of cet) values are not determined by Blanchard and Kiyetaki (1987), sfect competition in general equilil ts of aggregate demand and supply lassical framework assuming monol ean an evorennue number of firme

4. Add sticky note Tool - for making notes at specific points in the text.

Marks a point in the proof where a comment needs to be highlighted.

\section{How to use it}

- Click on the Add sticky note icon in the Annotations section.

- Click at the point in the proof where the comment should be inserted.

- Type the comment into the yellow box that appears.

lailu dilu suppiy silucks. Iviusl U1

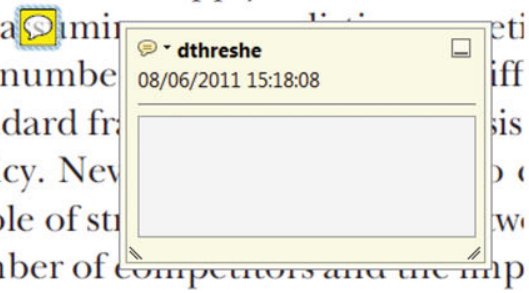
is that the structure of the secte 
5. Attach File Tool - for inserting large amounts of text or replacement figures.

Inserts an icon linking to the attached file in the appropriate pace in the text.

\section{How to use it}

- Click on the Attach File icon in the Annotations section.

- Click on the proof to where you'd like the attached file to be linked.

- Select the file to be attached from your computer or network.

- Select the colour and type of icon that will appear in the proof. Click OK.

E N D

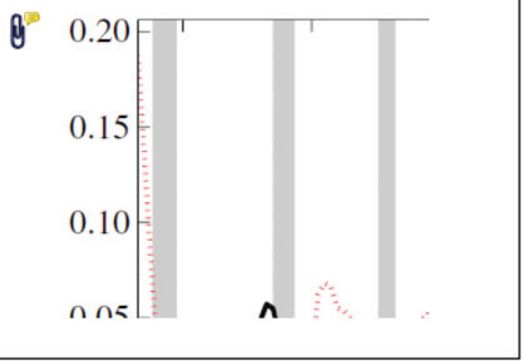

6. Add stamp Tool - for approving a proof if no corrections are required.

B. Inserts a selected stamp onto an appropriate place in the proof.

How to use it

- Click on the Add stamp icon in the Annotations section.

- Select the stamp you want to use. (The Approved stamp is usually available directly in the menu that appears).

- Click on the proof where you'd like the stamp to appear. (Where a proof is to be approved as it is, this would normally be on the first page).

of the Dusiness cycie, starting with the on perfect competition, constant ret ef otaki (1987), has introduced produc general equilibrium models with nomin

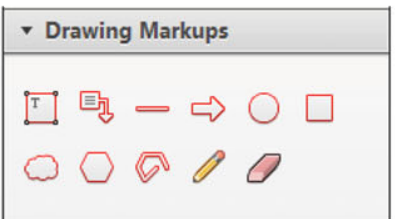

How to use it

Click on one of the shapes in the Drawing Markups section.

- Click on the proof at the relevant point and draw the selected shape with the cursor.

- To add a comment to the drawn shape, move the cursor over the shape until an arrowhead appears.

- Double click on the shape and type any text in the red box that appears.
7. Drawing Markups Tools - for drawing shapes, lines and freeform annotations on proofs and commenting on these marks.

Allows shapes, lines and freeform annotations to be drawn on proofs and for comment to be made on these marks.

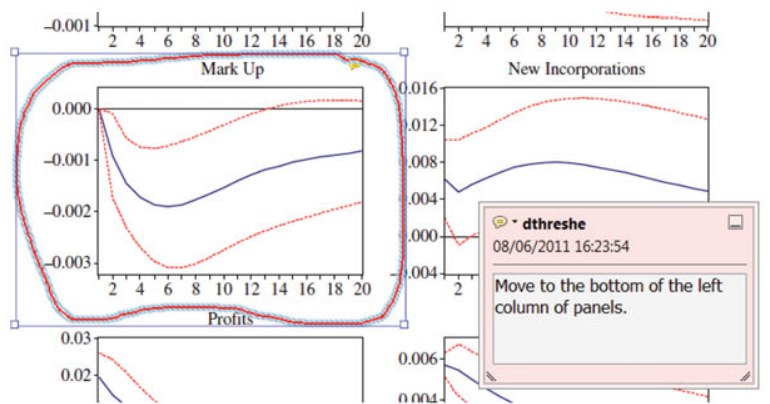

For further information on how to annotate proofs, click on the Help menu to reveal a list of further options:

\begin{tabular}{|l|l|l|l|l|}
\hline 2- ecoj_2384_CrxRev2_EV_19-Jul-10.pdf - Adobe Reader \\
\hline File Edit View Window
\end{tabular}




\section{Proteomics \\ Clinical Applications}

Please correct your galley proofs and return them within $48 \mathrm{~h}$ of receipt.

Note: The editors reserve the right to publish your article without your corrections if the proofs do not arrive in time.

Important

Please note that, due to the size constraints of emailed attachments, the attached proofs are low resolution; however, please be assured that high resolution versions will be used for printing.

Check the enclosed galley proofs very carefully, paying particular attention to the formulae, figures, numerical values, and tabulated data. An author query (AQ) in the border indicates unclear or missing information that requires your attention. For the complete query, please consult the attached list. Note that the author is liable for damages arising from incorrect statements, including misprints.
Your corrections should be provided as a list (e.g. in Word format), including the page number, column, section number and line at which the correction occurs. In addition, we ask that you provide a scanned pdf of the proof with corrections, if possible, to reduce the risk of errors.

Please return your corrections by email to the following address:

E-Mail: wiley.weinheim@aptaracorp.com

Please limit corrections to printing errors; costs incurred for any further changes or additions will be charged to the author, unless such changes have been accepted by the editor.

Reprints may be ordered by filling out the accompanying form and should be returned to the Editorial Office. 


\section{PROTEOMICS}

Please complete this form and return it via E-Mail or Fax:

Reprint Order Form

E-mail: proteomics@wiley.com

Fax: +49 (0) 6201606525

Wiley-VCH Verlag GmbH \& Co. KGaA

Proteomics Clinical Applications

Boschstr. 12

69469 Weinheim

Germany
Manuscript No.: 201300133

Costumer No.: (if available)

Purchase Order No.:

Author:

Date:

\section{Reprints}

Reprints are available at the rates given below only if ordered now. Please note that prices will be substantially higher after publication of the issue. All given prices are including postage and handling charges and excluding tax (VAT). If more than 500 copies are ordered, special prices are available upon request.

Please send me and bill me for

no. of reprints via

$\square$ airmail (+ 25 Euro)
$\square$ surface mail
$\square$ Fedex No.:

no. of copies of this issue

(1 copy: 20 Euro)

$$
\begin{gathered}
\text { via } \square \text { airmail (+ } 25 \text { Euro) } \\
\square \text { surface mail } \\
\square \text { Fedex No.: }
\end{gathered}
$$

high-resolution PDF file (330 Euro).

My e-mail address:

\section{$\rightarrow$ Special Offer}

If you order 200 or more reprints you will get a PDF file for half price. reprints and a PDF file.

Please note: It is not permitted to present the PDF file on the internet or on company homepages

\section{My VAT number is:}

\section{Information regarding VAT}

Please note that from German sales tax point of view, the charge for Reprints, Issues or Posters is considered as "supply of goods" and therefore, in general, such delivery is a subject to German sales tax. However, this regulation has no impact on customers located outside of the European Union. Deliveries to customers outside the Community are automatically tax-exempt. Deliveries within the Community to institutional customers outside of Germany are exempted from the German tax (VAT) only if the customer provides the supplier with his/her VAT number. The VAT number (value added tax identification number) is a tax registration number used in the countries of the European Union to identify corporate entities doing business there. It starts with a country code (e.g. FR for France, GB for Great Britain) and follows by numbers.
Mail reprints / copies of the issue to:

Send bill to:

\section{Date, Signature}

\section{Credit Card Payment}

VISA, MasterCard, AMERICAN EXPRESS

Please use the Credit Card Token Generator located at the website below to create a token for secure payment. The token will be used instead of your credit card number.

\section{Credit Card Token Generator:}

https://www.wiley-vch.de/editorial_production/index.php

Please transfer your token number to the space below.

\section{Credit Card Token Number}

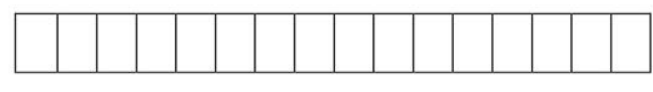

Wiley-VCH Verlag GmbH \& Co. KGaA; Location of the Company: Weinheim; Chairman of the Supervisory Board: Stephen Michael Smith,

Trade Register: Mannheim, HRB 432833, General Partner: John Wiley \& Sons GmbH,

Location: Weinheim, Trade Register Mannheim, HRB 432296,

Managing Directors: Bijan Ghawami, Dr. Jon Walmsley 
Die unten genannten Preise gelten nur für Sonderdrucke, die im Lauf des Jahres 2014 und vor dem Druck des Heftes bestellt werden. Mindestbestellmenge: 50 Exemplare. Lieferung: ca. 3 Wochen nach Erscheinen des Werkes, aus dem der Sonderdruck stammt.

Die Anfertigung von Sonderdrucken nach dem Druck einer Zeitschrift ist wesentlich teurer, da sie im Verlag und in der Druckerei zusätzliche Arbeitsgänge erfordert. Bitte bestellen Sie Ihre Sonderdrucke daher rechtzeitig und in ausreichender Stückzahl.

Bei Abnahme von mehr als 500 Exemplaren gelten Sonderpreise, die wir auf Anfrage mitteilen werden.

Ganze Hefte können von Autoren zu einem ermäßigten Preis bestellt werden.

Verpackung und Versandkosten (außer Luftpost) sind in den unten genannten Preisen enthalten. Die Mehrwertsteuer wird extra berechnet.

Sonderdrucke/Hefte werden per Schiff nach Übersee verschickt. Sollten Sie an einer schnelleren Beförderung per Luftpost interessiert sein, vermerken Sie dies auf beiliegendem Bestellformular. Bitte beachten Sie aber, dass Ihnen für diesen Versandweg die Kosten in Rechnung gestellt werden.

\section{Price List for Reprints (2014)}

The prices listed below are valid only for orders received in the course of 2014 and before the proofs pass for press. Minimum order is 50 copies. Delivery time will be approximately 3 weeks after the date of publication.

The production of reprints after a journal has been published is considerably more expensive since it requires extra operations on the publisher's and printer's side. Therefore, authors are requested to order reprints early and in sufficient numbers.

If more than 500 copies are ordered, special prices are available upon request.

Single issues are available to authors at a reduced price.

The prices include mailing and handling charges (with the exception of the additional costs incurred for air mail delivery). All Wiley-VCH prices are exclusive of VAT.

Reprints and issues are shipped by surface. If you are interested in receiving them by airmail mail please indicate this on the accompanying order form; however, please be aware that the costs incurred are considerably higher (surcharge Euro 25.00).

\begin{tabular}{|c|c|c|c|c|c|c|}
\hline \multirow{3}{*}{$\begin{array}{l}\text { Sonderdrucke/Reprints } \\
\text { Umfang (Seiten) } \\
\text { Size (pages) }\end{array}$} & \multicolumn{6}{|c|}{ Preis bei Abnahme von/Price for orders of (in Euro) } \\
\hline & 50 & 100 & 150 & 200 & 300 & 500 \\
\hline & Expl./copies & Expl./copies & Expl./copies & Expl./copies & Expl./copies & Expl./copies \\
\hline $1-4$ & $345,-$ & $395,-$ & $425,-$ & $445,-$ & $548,-$ & $752,-$ \\
\hline $5-8$ & $490,-$ & $573,-$ & $608,-$ & $636,-$ & $784,-$ & $1077,-$ \\
\hline $9-12$ & $640,-$ & $739,-$ & $786,-$ & $824,-$ & $1016,-$ & $1396,-$ \\
\hline $13-16$ & $780,-$ & $900,-$ & $958,-$ & $1004,-$ & $1237,-$ & $1701,-$ \\
\hline $17-20$ & $930,-$ & $1070,-$ & $1138,-$ & $1196,-$ & $1489,-$ & $2022,-$ \\
\hline $\begin{array}{l}\text { je weitere } 4 \text { Seiten/ } \\
\text { for every additional } \\
4 \text { pages }\end{array}$ & $147,-$ & $169,-$ & $175,-$ & $188,-$ & $231,-$ & $315,-$ \\
\hline Hefte/lssues & 1 Exemplar/ & py: 25,- Eur & PDF ( & resolution) & -Euro & \\
\hline
\end{tabular}

Postage and handling charges included. All Wiley-VCH prices are exclusive of VAT.

Prices are subject to change. 


\section{Proteomics Clinical Applications}

\section{Supporting Information} for Proteomics

\section{DOI 10.1002/prca.201300133}

Renata Fajardo Bonin, Alex Chapeaurouge, Jonas Perales, José Godinho da Silva Jr., Hilton Jorge do Nascimento, Ana Paula D'Alincourt Carvalho Assef and José Procópio Moreno Senna

Identification of immunogenic proteins of the bacterium Acinetobacter baumannii using a proteomic approach 